\title{
Positron emission tomography in asymptomatic gene carriers of Machado-Joseph disease
}

\author{
Bing-wen Soong, Ren-shyan Liu
}

\begin{abstract}
Objectives-The metabolic changes in the brain of symptomatic subjects affected with Machado-Joseph disease have been previously documented using PET with fluorine-18-fluorodeoxyglucose (FDG). The aim of this study was to evaluate these changes in asymptomatic MachadoJoseph disease gene carriers.

Methods-Seven asymptomatic MachadoJoseph disease gene carriers, identified using a molecular test, and 10 normal control subjects were recruited for PET studies using FDG. Regional uptake ratios of FDG were calculated from the radioactivity of the cerebellar hemispheres, brainstem, and the temporal, parietal and occipital cortices, divided by the activity in the thalamus.
\end{abstract}

Results-In comparison with data obtained from normal control subjects, there was significantly decreased FDG utilisation in the cerebellar hemispheres, brainstem, and occipital cortex, and increased FDG metabolism in the parietal and temporal cortices of asymptomatic Machado-Joseph disease gene carriers, suggesting preclinical disease activity. Discriminant analysis of regional FDG uptake correctly classified genetic status (Machado-Joseph disease mutation carriers $v$ mutation negative subjects) in 25 of 25 subjects $(100 \%$ sensitivity and $100 \%$ specificity), and clinical status (asymptomatic mutation carriers $v$ symptomatic patients) in 14 of 15 subjects $(100 \%$ sensitivity and $85.7 \%$ specificity).

Conclusion-Subclinical changes of FDG consumption, as measured by noninvasive PET, can act as an objective marker of preclinical disease activity in Machado-Joseph disease.

(F Neurol Neurosurg Psychiatry 1998;64:499-504)

Keywords: Machado-Joseph disease; positron emission tomography; asymptomatic gene carriers

Machado-Joseph disease (MIM 109150) is an autosomal dominantly inherited neurodegenerative disorder characterised pathologically by degeneration of the spinocerebellar tracts, dentate nuclei, pontine and vestibular nuclei, extrapyramidal structures (substantia nigra, locus coeruleus, and the pallidoluysian complex), and neuronal loss in motor cranial nerves, anterior horn cells, and the posterior root ganglion. ${ }^{12}$ The cerebral and cerebellar cortices and inferior olives are spared. ${ }^{3}$ Patients often present with cerebellar ataxia, pyramidal signs, and progressive external ophthalmoplegia. Bulging eyes, peripheral amyotrophy, and dystonia of varying severity may also be present. ${ }^{4}$ The natural course of this illness, with the average age at onset of symptoms in the late fourth decade of life, often results in many years of at risk status for those who have a parent with the disease. The insidious nature of Machado-Joseph disease often makes the exact age at onset of symptoms difficult to determine.

The Machado-Joseph disease gene has been isolated and characterised, ${ }^{5}$ and the mutation responsible for the disease has been shown to be an expansion of a trinucleotide CAG repeat that lies at the 3 ' terminal of the coding region. ${ }^{5}$ The identification of the characteristic CAG repeat expansion in theMachado-Joseph disease gene has since become the gold standard for the definitive diagnosis of the disease.

Positron emission tomography (PET) has been shown to be a useful tool in elucidating the pathophysiology of various movement disorders (Huntington's disease, ${ }^{6}$ Parkinson's disease, ${ }^{7}$ progressive supranuclear palsy, ${ }^{8}$ and spinocerebellar degeneration ${ }^{9}{ }^{10}$ ). Using PET with fluorine-18-fluoro-2-deoxy-D-glucose (FDG), we showed that relative brain glucose metabolism was significantly diminished in the cerebellar hemispheres, cerebellar vermis, brainstem, and cerebral occipital cortex in patients affected with Machado-Joseph disease. ${ }^{11}$ The present study of asymptomatic Machado-Joseph disease gene carriers was undertaken to consider the question of whether regional brain hypometabolism can be found years before onset of disease, the sensitivity of the PET in the detection of asymptomatic Machado-Joseph disease gene carriers, and whether the length of CAG repeat correlates with the severity of these metabolic changes. In addition, we performed discriminant function analysis to assess whether the genetic and clinical status of the subjects could be predicted from brain functional values.

The study of metabolic changes in the brain of Machado-Joseph disease gene carriers is of importance as it could potentially identify subjects who may be suitable for therapeutic intervention in the near future to establish timing of treatment, to gauge response, and to halt or slow the disease process years before clinical presentation.

\section{Patients and methods}

\section{SUBJECTS}

Previously, eight symptomatic subjects with Machado-Joseph disease were studied with PET using FDG. ${ }^{11}$ In this report seven 


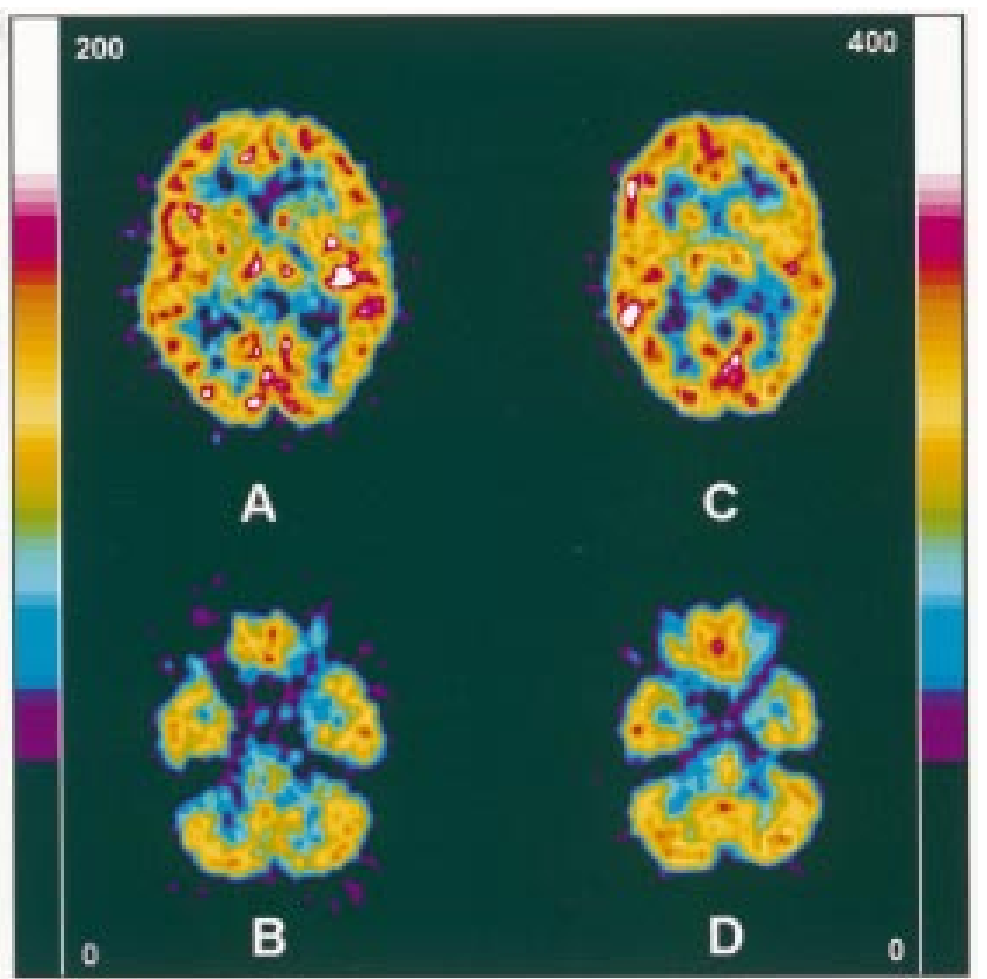

Figure 1 FDG PET in subject $5(A, B)$ who is an asymptomatic gene carrier of Machado-foseph disease, and a normal control subject $(C, D)$. Relative to the FDG uptake in the thalamus, the FDG uptake ratio is decreased in the cerebellar hemisphere, brainstem $(B)$, and occipital cortex $(A)$, but increased in the parietal and temporal cortices $(A)$. Squares represent the regions of interest marked in the thalamus, occipital and frontal cortices, brainstem, and cerebellum. Colour bars indicate regional brain FDG uptake in $n C i / m l$ extending from 0.0 to $200(A, B)$ and 0.0 to $400(C, D)$.

unrelated asymptomatic gene carriers of Machado-Joseph disease (four males and three females; age 27.7 (SD 11.4) years), identified by the presence of expanded CAG repeats (70.9 (SD 6.7)) in the Machado-Joseph disease gene, and 10 normal control subjects (four males and six females; age 46.9 (SD 11.8) years, range of CAG repeats 14-39) were recruited for investigation. All of the asymptomatic mutation carriers underwent careful neurological examination by an experienced board certified neurologist. None of them showed any sign of ataxia or other "soft" neurological signs. Informed consent was obtained from all subjects.

DNA ANALYSIS WITH QUANTITATIVE POLYMERASE CHAIN REACTION

Genomic DNA was isolated from buffy coat leucocytes as previously described, ${ }^{12}$ and analysed to determine the length of the CAG repeat in the Machado-Joseph disease gene. Polymerase chain reaction of genomic DNA was performed according to the method of Kawaguchi et al. ${ }^{5}$ Primers MJD52 and MJD25 were used to identify the triplet region. ${ }^{5}$ This technique identifies the number of CAG repeats in the Machado-Joseph disease gene. ${ }^{11}$

PET STUDIES

All subjects were awake, taking no medication known to affect CNS function, and blindfolded during the examination. The imaging device was an eight ring Scanditronix PC4096-15WB whole body PET scanner (Scanditronix, Swe- den) with an axial resolution of $6 \mathrm{~mm}$ and in plane resolution of $8 \mathrm{~mm}$ at the centre of the field of view. PET imaging was performed 45 to 75 minutes after injection of $10 \mathrm{mCi}(370$ $\mathrm{MBq})$ FDG. Visual interpretation and semiquantitative analysis of the PET images were conducted subsequently. The regions of interest (ROIs) were determined in the cerebellar hemispheres, brainstem, thalamus, and parietal, temporal, and occipital cortices by reference to an atlas of axial tomography. Extreme caution was exercised in the placement of ROIs to avoid potential contamination from adjacent anatomical structures. Data were collected from the ROIs by placing an $11 \times 11 \mathrm{~mm}$ square over each thalamus, an $11 \times 11 \mathrm{~mm}$ square over the occipital cortex, an $10 \times 15 \mathrm{~mm}$ rectangle over the frontal, temporal, and parietal cortices (fig $1 \mathrm{C}$ ), a $11 \times 22 \mathrm{~mm}$ parallelogram over each cerebellar hemisphere, and an $11 \times 15 \mathrm{~mm}$ rectangle over the brainstem (fig $1 \mathrm{D}$ ). Each ROI was centred over a local peak in FDG metabolism. Uptake of FDG was calculated as $\mathrm{nCi} / \mathrm{ml}$. Regional uptake ratios were then calculated from the radioactivity of the cerebellar hemispheres, brainstem, and the temporal, parietal, and occipital cortices, divided by the activity in the thalamus.

\section{STATISTICAL ANALYSIS}

Age, CAG repeat number, and regional brain FDG uptake ratios are presented as range and mean (SD). Differences of brain FDG uptake ratios in asymptomatic gene carriers of Machado-Joseph disease, symptomatic patients with Machado-Joseph disease, and control subjects are presented as $95 \%$ confidence intervals (95\% CIs). A Mann-Whitney $U$ test was used to assess the statistical significance. The association between the age of asymptomatic gene carriers, the size of the trinucleotide repeat sequence, and the regional brain uptake ratios of FDG were evaluated through Spearman's correlation analyses. Discriminant function analysis was used to categorise subjects on the basis of their FDG values in the cerebellar hemispheres, brainstem, and occipital, temporal, and parietal cortices. Specificity ((true negative)/(true negative + false positive)) and sensitivity ((true positive)/(true positive + false negative)) were then calculated, based on discriminant analysis categorisation obtained from each of the above mentioned variables.

\section{Results}

Figure 1 shows typical brain FDG consumption scans in one of the asymptomatic Machado-Joseph disease gene carriers (subject 5) and one normal control subject. Table 1 shows the age, the CAG repeat number in the Machado-Joseph disease gene, and the individual regional brain uptake ratios of FDG of the seven asymptomatic Machado-Joseph disease gene carriers.

Significantly lower regional brain uptake ratios of FDG compared with that of normal subjects, were found over the cerebellar hemisphere (Machado-Joseph disease gene carriers $0.72-0.84$, control 0.88 (SD 0.03)), brainstem (Machado-Joseph disease gene 
Table 1 Regional brain uptake ratios of FDG in asymptomatic gene carriers of Machado-Foseph disease (MFD)

\begin{tabular}{|c|c|c|c|c|c|c|c|c|}
\hline & \multicolumn{7}{|c|}{ Asymptomatic MFD gene carriers } & \multirow{2}{*}{$\begin{array}{l}\text { Control subjects } \\
(\text { mean }(S D)) \\
(n=10)\end{array}$} \\
\hline & Subject 1 & Subject 2 & Subject 3 & Subject 4 & Subject 5 & Subject 6 & Subject 7 & \\
\hline Age (y) & 13 & 22 & 23 & 25 & 25 & 39 & 47 & $46.9(11.8)$ \\
\hline CAG repeat number & 80 & 63 & 76 & 73 & 73 & 62 & 69 & $21.7(7.0)$ \\
\hline $\mathrm{CH} / \mathrm{TH}$ & $0.72(82)$ & $0.77(88)$ & $0.82(93)$ & $0.79(90)$ & $0.78(89)$ & $0.81(92)$ & $0.84(95)$ & $0.88(0.03)$ \\
\hline $\mathrm{BS} / \mathrm{TH}$ & $0.73(94)$ & $0.59(76)$ & $0.76(97)$ & $0.60(77)$ & $0.65(83)$ & $0.68(81)$ & $0.77(99)$ & $0.78(0.08)$ \\
\hline $\mathrm{O} / \mathrm{TH}$ & $0.84(91)$ & $0.78(85)$ & $0.86(93)$ & $0.87(95)$ & $0.78(85)$ & $0.97(105)$ & $0.95(103)$ & $0.92(0.04)$ \\
\hline $\mathrm{P} / \mathrm{TH}$ & $1.0(104)$ & $0.97(101)$ & $1.20(125)$ & $1.04(108)$ & $1.08(113)$ & $1.20(125)$ & $1.05(109)$ & $0.96(0.03)$ \\
\hline $\mathrm{T} / \mathrm{TH}$ & $0.95(106)$ & $0.92(102)$ & $1.11(123)$ & $1.09(121)$ & $1.00(111)$ & $1.04(116)$ & $1.02(113)$ & $0.90(0.04)$ \\
\hline
\end{tabular}

Numbers in parentheses for the asymptomatic MJD gene carriers represent percentage of each ratio compared with the mean of control subjects.

$\mathrm{CH}=$ cerebellar hemisphere; $\mathrm{BS}=$ brainstem; $\mathrm{O}=$ occipital; $\mathrm{P}=$ parietal; $\mathrm{T}=$ temporal; $\mathrm{TH}=$ thalamus.

carriers $0.59-0.77$, control 0.78 (SD 0.08), and the occipital cortex (Machado-Joseph disease gene carriers $0.78-0.97$, control 0.92 (SD 0.04) (table 2 and fig 2). By contrast, significantly higher regional brain uptake ratios of FDG were found over the parietal (Machado-Joseph disease gene carriers 0.971.20, control 0.96 (SD 0.03)) and temporal (Machado-Joseph disease gene carriers 0.921.11 , control 0.90 (SD 0.04)) cortices (table 2 and fig 2). Comparison of the regional FDG uptake ratios between the asymptomatic gene carriers and the patients with Machado-Joseph disease also disclosed significant differences, in the parietal, temporal, and occipital cortices and the cerebellum (table 2).

No significant correlation was found between the size of CAG repeat and the regional brain uptake ratios of FDG. However, a tentative trend towards correlation seemed to be present between the age of the asymptomatic gene carriers and the regional FDG uptake ratio in the cerebellar hemisphere $(r=0.83)$ and occipital cortex $(r=0.77)$.

Discriminant function analysis was performed on the three groups (asymptomatic Machado-Joseph disease mutation carriers, mutation negative controls, and patients with Machado-Joseph disease) considering FDG uptake in the cerebellar hemispheres, brainstem, and occipital, parietal, and temporal cortices each as separate variables. The best categorisations between normal controls and asymptomatic Machado-Joseph disease mutation carriers were obtained with cerebellar FDG uptake ratios which showed an $86 \%$ sensitivity and a $100 \%$ specificity, and with temporal FDG uptake ratios which disclosed a $71.4 \%$ sensitivity and a $100 \%$ specificity. However, when considering the two dependent variables together, discriminant analysis classification was consistent with the genetic status in 17 of 17 subjects with a $100 \%$ sensitivity and a $100 \%$ specificity. The best categorisation between normal controls and symptomatic subjects was obtained with cerebellar FDG uptake ratios, which showed a $100 \%$ sensitivity and $100 \%$ specificity. Discriminant function analysis on FDG uptake ratios between asymptomatic mutant gene carriers and symptomatic patients was consistent with clinical status in 14 of 15 subjects with a $100 \%$ sensitivity and an $85.7 \%$ specificity in the parietal cortex. The one remaining person (subject

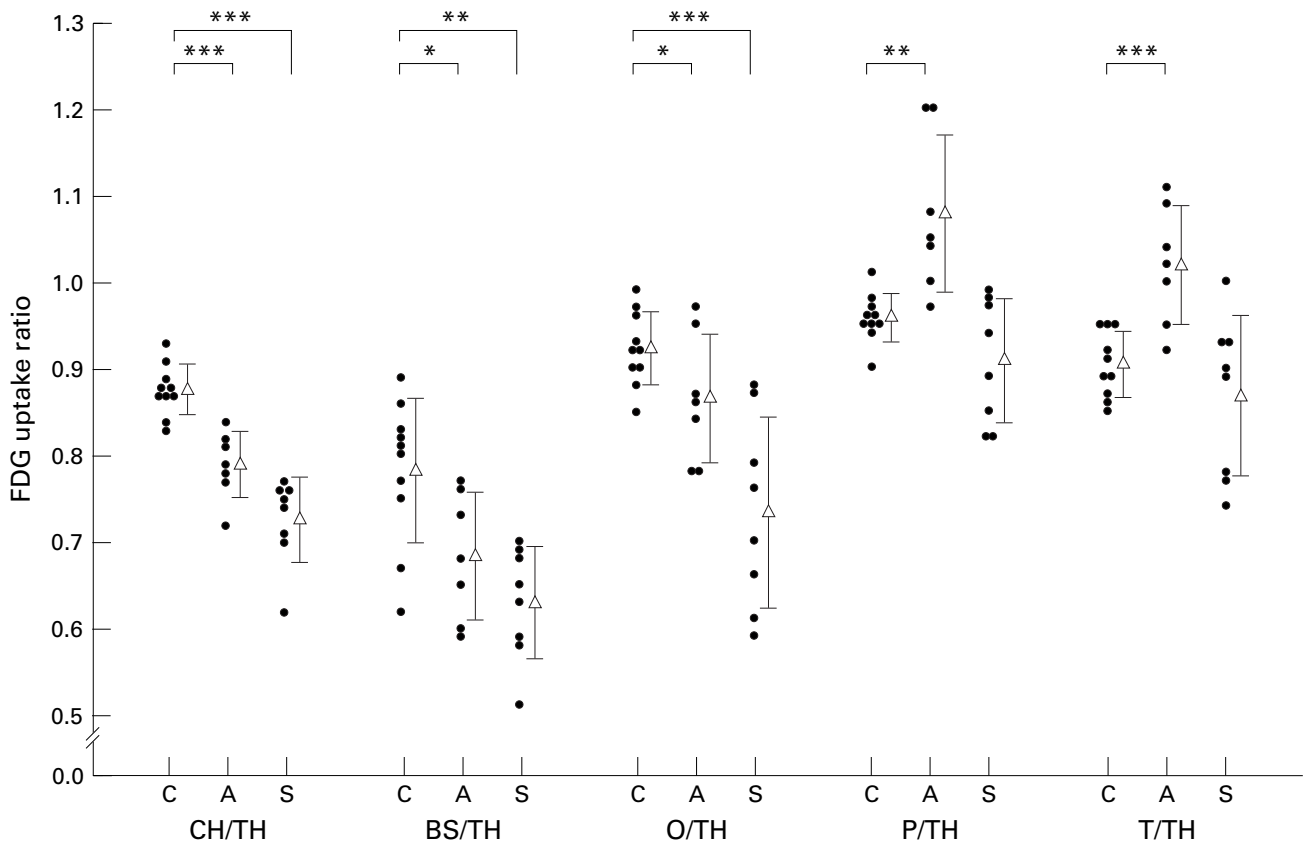

Figure 2 Scatter diagrams of local brain metabolic ratio for glucose in asymptomatic gene carriers $(A)$ of

Machado-foseph disease compared with normal control subjects (C) and symptomatic people (S) with Machado-foseph disease. ${ }^{11}$ Each point represents the average value for each case in the structure specified. The triangles with error bars depict the mean (SD) value for each group. $C H=$ cerebellar hemisphere; $B S=$ brainstem; $O=$ occipital; $P=$ parietal; $T=$ temporal; TH=thalamus. ${ }^{\star} p<0.05 ;{ }^{\star \star} p<0.01 ;{ }^{\star \star \star} p<0.001$. 
Table 2 Comparison of regional brain uptake ratios of FDG in asymptomatic Machado-foseph disease (MFD) gene carriers, patients with Machado-Foseph disease, and normal controls

\begin{tabular}{|c|c|c|c|c|c|c|}
\hline & \multicolumn{3}{|c|}{ Patients with $M F D(n=8)^{11}$} & \multicolumn{2}{|c|}{ Asymptomatic gene carriers $(n=7)$} & \multirow{2}{*}{$\begin{array}{l}\text { Control subjects } \\
\text { mean }(S D) \\
(n=10)\end{array}$} \\
\hline & FDG uptake ratios & Difference $(95 \% C I) t$ & Difference $(95 \%$ CI $) \neq$ & FDG uptake ratios & Difference $(95 \%$ CI)S & \\
\hline \multicolumn{2}{|c|}{ Age $(y$, mean $(S D))$} & $28.9(10.3)$ & & & $27.7(11.4)$ & $46.9(11.8)$ \\
\hline \multicolumn{2}{|c|}{$\mathrm{CAG}$ repeat number (mean (SD)) } & $73.4(6.0)$ & & & $70.9(6.7)$ & $21.7(7.0)$ \\
\hline $\mathrm{CH} / \mathrm{TH}$ & $0.73(\mathrm{SD} 0.05)$ & $\begin{array}{l}-0.15 \\
(-0.19 \text { to }-0.11)^{\star \star \star}\end{array}$ & $\begin{array}{l}-0.06 \\
(-0.11 \text { to }-0.01)^{\star}\end{array}$ & $0.79(\mathrm{SD} 0.04)$ & $\begin{array}{l}-0.09 \\
(-0.12 \text { to }-0.05)^{\star \star \star}\end{array}$ & $0.88(0.03)$ \\
\hline $\mathrm{BS} / \mathrm{TH}$ & $0.63(\mathrm{SD} 0.07)$ & $\begin{array}{l}-0.15 \\
(-0.23 \text { to }-0.07)^{\star \star}\end{array}$ & $\begin{array}{l}-0.05 \\
(-0.12 \text { to } 0.02)\end{array}$ & $0.68(\mathrm{SD} 0.07)$ & $\begin{array}{l}-0.10 \\
(-0.18 \text { to } 0.02)^{\star}\end{array}$ & $0.78(0.08)$ \\
\hline $\mathrm{O} / \mathrm{TH}$ & $0.73(\mathrm{SD} 0.11)$ & $\begin{array}{l}-0.19 \\
(-0.27 \text { to }-0.11)^{\star \star \star}\end{array}$ & $\begin{array}{l}-0.13 \\
(-0.23 \text { to }-0.03)^{\star}\end{array}$ & $0.86(\mathrm{SD} 0.07)$ & $\begin{array}{l}-0.06 \\
(-0.12 \text { to } 0.00)^{\star}\end{array}$ & $0.92(0.04)$ \\
\hline $\mathrm{P} / \mathrm{TH}$ & $0.91(\mathrm{SD} 0.01)$ & $\begin{array}{l}-0.05 \\
(-0.07 \text { to }-0.03)\end{array}$ & $\begin{array}{l}-0.16 \\
(-0.24 \text { to }-0.07)^{\star \star}\end{array}$ & $1.07(\mathrm{SD} 0.09)$ & $\begin{array}{l}0.11 \\
(0.05 \text { to } 0.17)^{\star \star}\end{array}$ & $0.96(0.03)$ \\
\hline $\mathrm{T} / \mathrm{TH}$ & $0.87(\mathrm{SD} 0.09)$ & $\begin{array}{l}-0.03 \\
(-0.10 \text { to } 0.04)\end{array}$ & $\begin{array}{l}-0.15 \\
(-0.23 \text { to }-0.06)^{\star \star}\end{array}$ & $1.02(\mathrm{SD} 0.07)$ & $\begin{array}{l}0.12 \\
(0.06 \text { to } 0.18)^{\star \star \star}\end{array}$ & $0.90(0.04)$ \\
\hline
\end{tabular}

${ }^{\star} p<0.05 ;{ }^{\star \star} p<0.01 ;{ }^{\star \star \star} p<0.01$

$\dagger$ Difference between regional FDG uptake ratios of subjects affected with MJD and that of control subjects.

$\ddagger$ Difference between regional FDG uptake ratios of subjects affected with MJD and that of asymptomatic gene carriers.

§Difference between regional FDG uptake ratios of asymptomatic gene carriers and those of control subjects.

$\mathrm{CH}=$ cerebellar hemisphere; $\mathrm{BS}=$ brainstem; $\mathrm{O}=$ occipital; $\mathrm{P}=$ parietal; $\mathrm{T}=$ temporal; $\mathrm{TH}=$ thalamus.

2) was an asymptomatic mutation carrier who was still serving in the army at the time of the PET measurement but was assigned to the category of symptomatic persons, indicating that this subject had an FDG uptake ratio in the parietal cortex indistinguishable from that in the affected patients.

\section{Discussion}

The role of PET in detecting subclinical disease has only been fully exploited in Huntington's disease. ${ }^{13-16}$ This is the first study to consider brain metabolism by PET in asymptomatic Machado-Joseph disease mutation carriers. Our results clearly show that subclinical changes in FDG consumption can be detected in vivo in all asymptomatic carriers of the Machado-Joseph disease mutation (table 1 and fig 2).

The difference in the age of asymptomatic gene carriers (27.7 (SD 11.4) years), symptomatic patients (28.9 (SD 10.3) years), and that of 10 normal control subjects (46.9 (SD 11.8) years) would not have any impact on baseline FDG concentrations (table 2). ${ }^{17}{ }^{18}$ In an initial study of 21 subjects, later extended to 40 subjects, it was found that mean hemispheric cerebral metabolic rate for glucose, and regional metabolic rate for glucose in bilaterally symmetric and midline brain regions that were examined, were not correlated significantly with age..$^{19} 20$

The thalamus was selected as the reference region for normalisation in our study for the following reasons: (1) The thalamus has been repeatedly shown to be unaffected and have a normal FDG metabolism in cases of olivopontocerebellar atrophy ${ }^{910}$ and Machado-Joseph disease. ${ }^{22}$ (2) FDG uptake could be calculated in the thalamus as well as in critical cerebral cortices from the same plane, allowing better comparison of data between these regions.

The metabolic changes detected with PET provide valuable information on the localisation of disease involvement. Using PET, Gilman et al found significant hypometabolism in the cerebellar hemispheres, cerebellar vermis, and brainstem in patients with sporadic and dominant olivopontocerebellar atrophy. ${ }^{9}{ }^{10}$ Although Machado-Joseph disease has been regarded as a disease that severely affects the cerebellum and brainstem and largely spares the cerebrum, our previous in vivo PET study, aimed specifically at patients with Machado-Joseph disease, disclosed that relative brain metabolism was significantly diminished in the cerebral occipital cortex, as well as the cerebellar hemispheres, cerebellar vermis, and brainstem, ${ }^{11}$ which was consistent with the results of Taniwaki et al. ${ }^{22}$ The finding of regional changes of FDG consumption in asymptomatic gene carriers in this report indicates involvement of these structures preceding the onset of symptoms, further underlying the importance of our finding. Although atrophy could undoubtedly contribute to the hypometabolism through partial volume effects, no evidence of cerebellum or brainstem atrophy was found in two of our presymptomatic subjects who underwent cranial CT.

Our results strongly suggest that the brain metabolism is also regionally increased in the temporal and parietal areas early in the course of Machado-Joseph disease (table 2 and fig 2). This increased glucose metabolism was not seen in affected patients with Machado-Joseph disease, ${ }^{11}$ and could result from a metabolic defect that impairs energy metabolism, resulting in increased glycolysis. ${ }^{23}$ We suspect that the cortices in these regions may be affected initially, as indicated by the increase in the FDG uptake ratio in our asymptomatic Machado-Joseph disease gene carriers. However, these regions may be less vulnerable to the harmful effects of this metabolic defect, leading to the slower decline in FDG uptake ratio in symptomatic cases of Machado-Joseph disease. Alternatively, the failure to see such raised relative parietal and temporal metabolism in symptomatic cases of Machado-Joseph disease may reflect an increased cortical involvement of the disease in these later stage patients. These two viewpoints both seem to deserve consideration when the findings of our study are considered. There is also the remote possibility that this finding is an artefact from the normalisation procedure using the thalamus as a reference area or the use of an older control group with potentially reduced brain metabolism. However, this normalisation is unlikely to have generated such an artefact in our study because similar assessments have 
previously been used. ${ }^{24}$ As we have described earlier, the use of an older control group was not associated with lower levels of metabolism in several studies ${ }^{17-20}$ and we have no reason to think that such an association exists. A quantitative PET study in more presymptomatic Machado-Joseph disease gene carriers will be performed to verify this finding.

Of note is that FDG consumption in the occipital cortex was reduced to $76 \%$ of the normal mean in one mutation carrier (subject 2) and in the parietal cortex increased to $125 \%$ of the normal mean in two other carriers (subjects 3 and 6), suggesting that subjects can remain neurologically intact on conventional examination with this degree of abnormal FDG uptake (table 1), despite the fact that a relatively high or low FDG uptake compared with a normal mean is not necessarily a good indication for neuronal dysfunction.

Previously we found that the CAG repeat in the Machado-Joseph disease gene was inversely correlated with the age at onset $(r=-0.77)$ and the duration of the illness with the cortical hypometabolism $(r=-0.80) .{ }^{11}$ With only seven asymptomatic Machado-Joseph disease gene carriers, covering a relatively narrow range of increased CAG repeat length, this study lacks the statistical power to show any correlation between the size of the CAG repeat sequence and the regional brain uptake ratios of FDG in the asymptomatic Machado-Joseph disease gene carriers. Moreover, although some linear trends towards a correlation could be seen between the age of the asymptomatic gene carriers and the regional FDG uptake ratios in the cerebellar hemisphere and the occipital cortex, these are also of questionable importance because of the few gene carriers studied.

The glucose metabolism data in the cerebellum, temporal, and parietal cortices were consistent with genetic status (Machado-Joseph disease mutation gene carriers $v$ mutation negative subjects) in 25 of 25 of subjects with a sensitivity of $100 \%$ and a specificity of $100 \%$. Furthermore, the clinical status (asymptomatic $v$ clinically affected) of the mutation carriers in this study was best categorised by the FDG metabolism in the parietal cortex in 14 of 15 subjects with a sensitivity of $100 \%$ and a specificity of $85.7 \%$. As Machado-Joseph disease is a late onset, progressive disorder with preclinical and clinical abnormalities which are age dependent, it is possible that an asymptomatic subject would be normal at some earlier time of life until a certain time point when preclinical changes occur. If enough asymptomatic carriers of younger age were studied, the sensitivity of PET might be considerably lower. The onset of these preclinical changes may be time dependent, occurring in the period just before the onset of symptoms. In other words, the PET changes may inversely correlate with the difference between the age of the asymptomatic subject at the time of PET and the age of onset of symptoms in the affected relative. However, this difference is often difficult to determine. The age at symptom onset may be similar in members of the same generation of the same family. However, there may be considerable variation of ages at onset of symptoms between members of the same family in different generations (anticipation phenomenon), ${ }^{11}$ which makes estimation of the difference very unreliable.

Measurement of regional brain metabolism by PET is non-invasive, and subclinical changes of FDG consumption seem to be an objective marker of disease activity. PET studies may have an important part to play in the selection and monitoring of asymptomatic Machado-Joseph disease gene carriers in future therapeutic trials of neuroprotective agents, infusions of growth factors, or implantation of fetal cells. However, any increases in FDG consumption that were to follow the use of neurotropic factors or tissue implantation in Machado-Joseph disease would have to be interpreted with caution, as increases in glial metabolism, for example, could mimic graft survival. The findings of an increase in FDG consumption after transplantation may suggest regeneration of intrinsic neurons.

In conclusion, by demonstrating the metabolic alterations, PET adds another dimension to our understanding of the brain. To clarify a possible correlation between the size of CAG trinucleotide repeat expansions and the severity and the rate of early metabolic changes in the brain, ${ }^{16}$ and to determine how far in advance of clinical onset of the disease these changes occur, ${ }^{16}$ further longitudinal PET investigation of large series of asymptomatic MachadoJoseph disease gene carriers are needed. Given the ready availability of relatively inexpensive DNA analysis for the Machado-Joseph disease gene, there is no justification at this point for the routine use of PET in the investigation of asymptomatic subjects at risk for MachadoJoseph disease, until information is available on the relation between changes in FDG uptake and the development of symptomatic disease.

We thank Ms Wen-yuan Shen for statistical analyses and Ms Pei-ching Lee for preparation of graphs, and gratefully acknowledge research supports from the National Science Council (Grant NSC 87-2314-B075-021) and Veterans General Hospital-Taipei (V354), Republic of China.

1 Coutinho P. Review of neuropathological findings in Machadofoseph disease: clinico-pathological correlation. Presented at the NIH: Research Initiatives on Machado foseph Disease. Bethesda: National Institute of Health, 1991.

2 Sudarsky L, Corwin L, Dawson DM. Machado-Joseph disease in New England: clinical description and distinction from the olivopontocerebellar atrophies. Mov Disord 1992; 7:204-8.

3 Takiyama Y, Nishizawa M, Tanaka $\mathrm{H}$, et al. The gene for Machado-Joseph disease maps to human chromosome 14q. Nat Genet 1993;4:300-4.

4 Harding AE. Clinical features and classification of inherited ataxias. Adv Neurol 1993;61:1-14. 5 Kawaguchi Y, Okamoto T, Taniwaki $\mathrm{M}$, et al. CAG chromosome 14q32.1. Nat Genet 1994;8:221-7.

6 Kuhl DE, Phelps ME, Markham CH, et al. Cerebral metabolism and atrophy in Huntington's disease determined by ${ }^{18} \mathrm{FDG}$ and computed tomographic scan. Ann Neurol 1982;12:425-34.

7 Leenders KL, Palmer AJ, Quinn N, et al. Brain dopamine metabolism in patients with Parkinson's disease measured with positron emission tomography. $\mathcal{f}$ Neurol Neurosurg Psychiatry 1986;49:853-60.

8 Otsuka M, Ichiya Y, Kuwabara Y, et al. Cerebral blood flow, oxygen and glucose metabolism with PET in progressive supranuclear palsy. Ann Nuclear Med 1989;3:111-8.

9 Gilman S, Markel DS, Koeppe RA, et al. Cerebellar and brainstem hypometabolism in olivopontocerebellar atrophy detected with positron emission tomography. Ann Neurol 1988;23:223-30.

10 Gilman S, Koeppe RA, Junck L, et al. Patterns of cerebral glucose metabolism detected with positron emission glucose metabolism detected with positron emission tomography differ in multiple system atrophy and ol
ivopontocerebellar atrophy. Ann Neurol 1994;36:166-75. 
11 Soong BW, Cherng CH, Liu RS, et al. Machado-Joseph disease: clinical, molecular and metabolic characterization disease: clinical, molecular and metabolic charact

12 Soong BW, Wang JT. A comparison of the Huntington's disease associated trinucleotide repeat between Chinese and white populations. F Med Genet 1995;32:404-5.

13 Hayden MR, Hewitt J, Martin WRW, et al. Studies in persons at risk for Huntington's disease. $N$ Engl $\mathcal{F}$ Med 1987;317:382-3

14 Mazziotta JC, Phelps ME, Pahl JJ, et al. Reduced cerebral glucose metabolism inasymptomatic subjects at risk for Huntington's disease. N Engl f Med 1987;316: 357-62.

15 Weeks RA, Piccini P, Harding AE, et al. Striatal D1 and D2 dopamine receptor loss in asymptomatic mutation carriers of Huntington's disease. Ann Neurol 1996;40:49-54.

16 Antonini A, Leenders KL, Spiegel R, et al. Striatal glucose metabolism and dopamine $\mathrm{D} 2$ receptor binding in asymptomatic gene carriers and patients with Huntington's tomatic gene carriers and patient

17 Frackowiak R, Gibbs JN Cerebral metabolism and blood flow in normal and pathological aging. In: P Magistretti, ed. Functional radionuclide imaging of the brain. New York: Raven Press, 305-9.
18 Alavi A, Dann R, Chawluk J, et al. Positron emission tomography imaging of regional cerebral glucose metabolism. Semin Nucl Med 1986;16:2-34.

19 Duara R, Margolin RA, Robertson-Tchabo EA, et al. Cerebral glucose utilization, as measured with positron emission tomography in 21 resting healthy men between the ages of 21 and 83 years. Brain 1983;106:761-75.

20 Rapoport SI, Duara R, Horwitz B, et al. Brain aging in 40 healthy men: rCMRglc and correlated functional activity in various brain regions in the resting state. $\mathcal{F}$ Cereb Blood Flow Metab 1983;3(suppl 1):5484

21 Rosenthal G, Gilman S, Koeppe RA, et al. Motor dysfunction in olivopontocerebellar atrophy is related to cerebral metabolic rate studied with positron emission tomography. Ann Neurol 1988;24:414-9.

22 Taniwaki T, Sakai T, Kobayashi T, et al. Positron emission tomography (PET) in Machado-Joseph disease. I Neurol Sci 1997;145:63

23 Gilman S, Junck L, Markel DS, et al. Cerebral glucose hypermetabolism in Friedreich's ataxia detected with positron emission tomography. Ann Neurol 1990;28:750-7.

24 Suchowersky O, Hayden MR, Martin WRW, et al. Cerebral metabolism of glucose in benign hereditary chorea. Mov Disord 1986;1:33-44.

\section{NEUROLOGICAL STAMP}

\section{Albrecht von Graefe (1828-70)}

Von Graefe, who was of gigantic importance in ophthalmology, died at the early age of 42 . By the age of 39 Von Graefe was internationally a unique figure and presided and dominated over the entire 3rd International Congress of Ophthalmology held in Paris in $1867 . \mathrm{He}$ read four papers including a classic description of choroid tubercles, but his most notable contribution was his exposition of his "modified linear extraction" as a new technique for the operation of cataract.

His contributions to ophthalmology were multiple. His name is eponymously remembered in the von Graefe sign in exophthalmic goitre and the von Graefe extraction knife. Ophthalmology developed through the application of the ophthalmoscope by von Graefe. His clinical contributions included the physiology of the oblique extraocular muscles and the symptoms of ocular paralysis, silver nitrate treatment of conjunctivitis, description of the various types of hemianopia, the efficacy of iridectomy in acute glaucoma, occlusion of the central retinal artery by emboli, the recognition of papilloedema, and the recognition of optic neuritis rather than paralysis of the optic nerve as being a cause of central visual failure.

Von Graefe died from tuberculosis. In 1882 his statue (with the ophthalmoscope) was erected in the garden of Charite Hospital in Berlin, and later relocated to Shuman Avenue.

Along with Donders, von Graefe founded the Archiv für Ophthalmologie, which did so much to raise the status of this specialty. Donders and Arlt became the editors. A stamp was issued by West Germany (West Berlin) in 1978 on the 150th year of the birth of von Graefe. (Stanley Gibbons B553, Scott 9N417).

L F HAAS

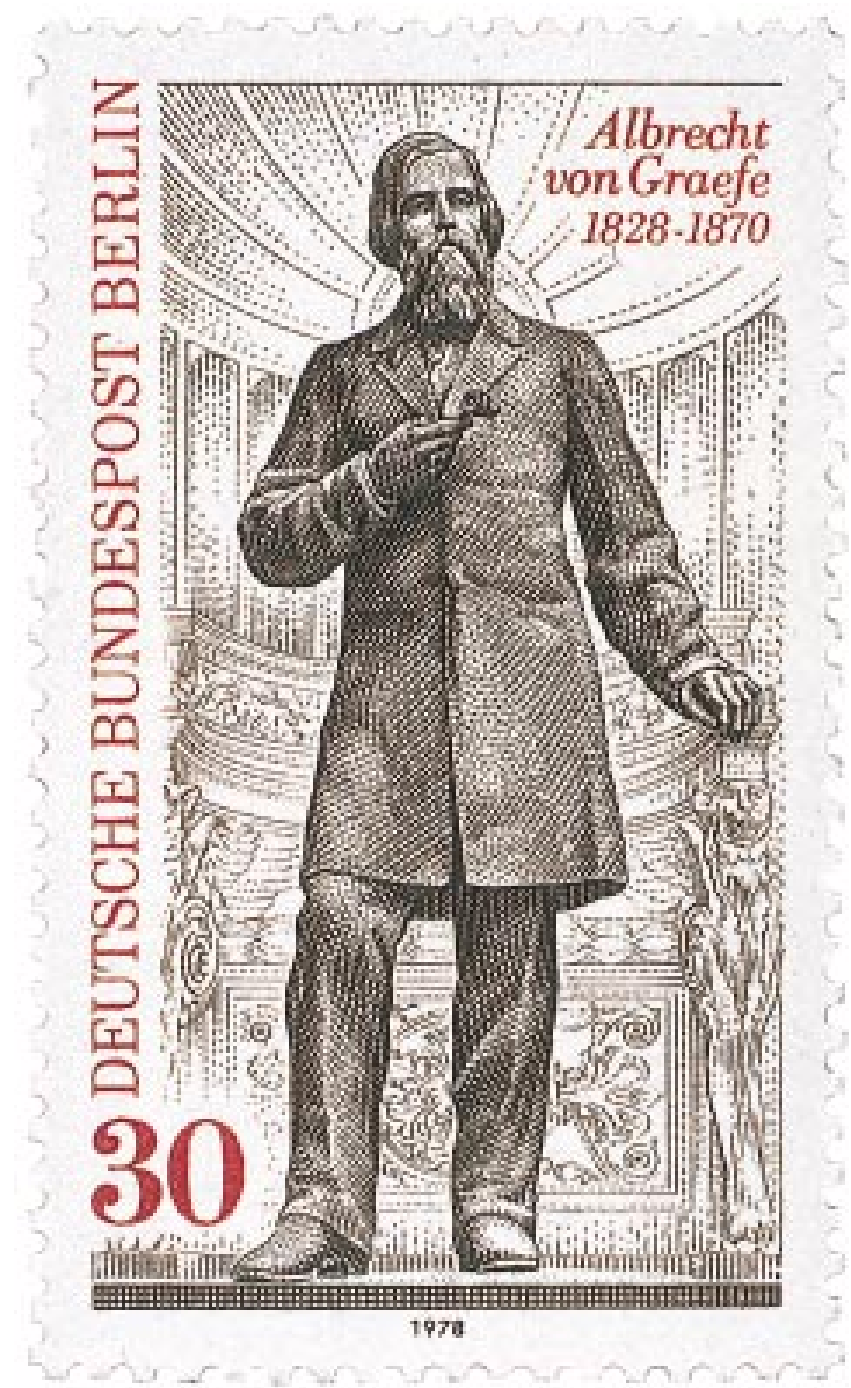

